\title{
28 Research Square \\ Breeding for chemical camouflage the case of salmon kairomones and resistance to salmon lice infectivity
}

\section{Gareth Difford ( $\nabla$ gareth.difford@nofima.no)}

Norwegian Institute of Food, Fisheries and Aquaculture Research https://orcid.org/0000-0002-6792-8722

John-Erik Haugen

Norwegian Institute of Food, Fisheries and Aquaculture Research

Muhammad Luqman Aslam

Norwegian Institute of Food, Fisheries and Aquaculture Research

Lill-Heidi Johansen

Norwegian Institute of Food, Fisheries and Aquaculture Research

Mette Breiland

Norwegian Institute of Food, Fisheries and Aquaculture Research

Borghild Hillestad

Benchmark Genetics Norway AS

Matt Baranski

MOWI AS

Solomon Boison

MOWI AS

\section{Hooman Moghadam}

Benchmark Genetics Norway AS

\section{Celeste Jaqc}

Norwegian Institute of Food, Fisheries and Aquaculture Research

\section{Article}

Keywords: salmon lice, ectoparasites, kairomones

Posted Date: August 11th, 2021

DOI: https://doi.org/10.21203/rs.3.rs-620617/v1

License: @ (i) This work is licensed under a Creative Commons Attribution 4.0 International License. Read Full License 


\section{Abstract}

Salmon lice are ectoparasites that threaten wild and farmed salmonids. Artificial selection of salmon for resistance to the infectious copepodid lice stage currently relies on in vivo challenge trials on thousands of salmon a year. We found that salmon emit a bouquet of kairomones which the lice use to find and infect the salmon. Some of these compounds vary between families and could be used as a more direct and ethical measurements of lice resistance for breeding farmed salmon.

\section{Main}

According to fossil records, for almost as long as there have been fish, they have been parasitized by copepods ${ }^{1}$. Salmon lice (Lepeophtheirus salmonis) are no exception and have coevolved to parasitize their Atlantic salmon (Salmo salar) hosts over the last (c $11 \mathrm{Ma})^{2}$. Host-parasite co-evolution is typically a rapid and reciprocal process where each species counter adapts the other's defences, essentially amounting to a zerosum game (i.e. Red Queen hypothesis) ${ }^{3}$. Since the intensification of Atlantic salmon farming in the second half of the twentieth century, salmon lice have become an intractable problem, having devastating effects on both wild and captive Atlantic salmon ${ }^{4}$. Chemical treatments have been followed by swift and successive salmon lice adaptation and resistance ${ }^{5-7}$, suggesting that repeated reintroduction of naïve salmon at high densities in sea cages may disproportionately favour parasitic adaptation. Strategies which prevent the parasite attaching to salmon have shown the most promise in breaking the host/parasite coevolutionary arms race ${ }^{6}$. A fundamental question is if it is possible to re-establish the host-parasite equilibrium at a steady state that ensures sustainable and ethical Atlantic salmon production?

Artificial selection for host resistance to attachment by the free-living larval phase (copepodids) is a strong approach $^{8}$. However, identifying genetically elite Atlantic salmon, relies on standardised in vivo parasite challenge trials on thousands of informant fish (siblings to breeding candidates) each generation. In addition to being a less efficient indirect method of selection, there are serious logistical and ethical limitations to challenge testing. All the while, the underlying molecular basis for host resistance to parasite infection remains undescribed. The key to salmon lice resistance may lie in circumventing how the free-swimming copepodid identifies a suitable host in a vast ocean environment. Kairomones are semiochemical compounds emitted by an organism that provide a direct benefit to another organism, often to the detriment of the emitting organism. Kairomones that govern host detection in biting insects such as mosquitoes are well-described and are predominantly volatile organic compounds $(\mathrm{VOCs})^{9}$, yet it's only recently that the importance of understanding the roles of VOC kairomones in aquatic species is being realized ${ }^{10}$. Copepodid antennules are activated by Atlantic salmon conditioned water ${ }^{11}$ which induces positive rheotactic swimming behaviour ${ }^{12}$, suggesting Atlantic salmon may release kairomones that aid copepodids in seeking a host.

We screened 5,750 Atlantic salmon from two distinct farmed strains for resistance to copepodid infection in two separate challenge trials. The first strain represented a broad genetic base with no documented artificial selection for resistance against salmon lice, and the challenge test was performed across a range of temperatures representing the thermal spectrum for Atlantic salmon farming $\left(5^{\circ} \mathrm{C}, 10^{\circ} \mathrm{C}, 17^{\circ} \mathrm{C}\right)(\mathrm{Temp})$. The second strain represented divergent genetic lines after three generations of selection for salmon lice resistance, representing high and low lice resistant lines (Gen). In Temp we sampled the skin mucus from the $1 \%$ of fish 
with the highest $(n=24)$ and the lowest $(n=24)$ copepodid infection. In Gen we randomly sampled mucus from $10 \%(n=24)$ fish across families within divergent lines. Using these data, we address two main questions: (1) which volatile organic compounds (VOCs) are associated with copepodid infectivity; (2) how much of the genetic and phenotypic variation in salmon lice resistance is explained by these VOCs? Overall, our goal was to understand the molecular mechanisms of salmon lice resistance and identify compounds for future directed phenotypes.

Across all copepodite challenges, large differences in infectivity were observed, independent of host size (Fig. 1a). We observed co-occurrence of two of the five VOCs differentially expressed across both populations' mucosal VOC bouquets (Fig. 1b and Fig. 1c). Despite both strains being cultured under the same conditions and on the same diet, we observed differences between the strains for compounds (Fig. 1c), raising questions about strain specific kairomones or the possibility for dietary influence on parents or during early life. We identified 3,5,5-trimethylcyclohex-2-en-1-one ${ }^{13}, 1$-octen-3-ol ${ }^{13,14}$ and 6-methyl-5-hepten-2-one ${ }^{9,15}$ as putative kairomones, consistent with biting insects and behavioural studies in salmon lice. Whilst compounds 1-penten3-ol and benzene are novel putative kairomones in Atlantic salmon.

Across all three water temperature challenges, VOCs were significantly expressed in fish with high lice infection (ANOVA 1df $p$ < 0.005) (Fig. 1d, Fig. 1e and Fig. 1f), strengthening the assertion that VOC expression is modulated by the host and not a response to water temperature induced metabolic rate. Significant differential expression was also observed for 1-octen-3-ol, 3,5,5-trimethylcyclohex-2-en-1-one and benzene, between the divergent genetic lines for lice resistance (Fig. 1g), demonstrating that selection for resistance against salmon lice has resulted in a correlated response in mucosal VOC bouquet composition. No significant difference was observed for 6-methyl-5-hepten-2-one between the genetically resistant and susceptible lines, opening questions on the environmental triggers for variation in this compound under standardised water temperatures and diet (Fig. 1g).

Genomic analysis revealed that lice infection is significantly heritable across populations $\left(h^{2}=0.23\right)(F i g .2)$ as reported previsouly ${ }^{8}$ and identified the host genetic potential to resist lice infection with high reliability. Quantitative genetic analysis revealed that family variation explained between $47-59 \%$ of the variation in 1octen-3-ol, trimethylcyclohex-2-en-1-one and benzene across populations (Fig. 2). Crucially, phenotypic expression of 1-octen-3-ol and 3,5,5-trimethylcyclohex-2-en-1-one were also correlated to the host genetic potential to resist copepodite infection $(r=0.59-0.74)$. There is family differences in VOCs which can be exploited by breeding and these explain variation in host resistance to copepodid attachment.

Together these results demonstrate that there is a direct link between host variation in skin mucosal VOCs and copepodite infectivity. Crucially, selection for resistance to salmon lice has indirectly resulted in decreased expression of key VOCs and the same VOCs explain a large proportion in the genetic differences between salmon. These results suggest that masking or camouflaging the expression of mucosal VOCs may impair copepodite host seeking behaviours and the completion of the parasitic lifecycle. If the measurement of inherent mucosal VOC profiles on individual breeding candidates can be done on a large scale, it has enormous potential to enable more efficient direct selection for lice resistance and is an ethical alternative to copepodid lice challenges. 


\section{Methods}

Salmon lice in vivo infection challenges:

All experiments were performed in strict accordance with the National Animal Research Authority in Norway (approval numbers 13569 Temp and $13571 \mathrm{Gen}$ ).

Two populations of Atlantic salmon (MOWI and Benchmark Genetics strains) were challenged with salmon lice in this study. The Benchmark Genetics fish were offspring from divergent lines (three families per line with 80 fish each) which have undergone multiple generations of selection to salmon lice resistance and were cultured at a standard water temperature $10^{\circ} \mathrm{C}$. The MOWI strain (50 families) with no artificial selection history for lice resistance were cultured at $10^{\circ} \mathrm{C}$ and then gradually adjusted to the range of water temperatures $\left(5^{\circ} \mathrm{C}, 10^{\circ} \mathrm{C}\right.$, $17^{\circ} \mathrm{C}$ ). All fish were cultured at the Aquaculture Research Station in Troms $\varnothing$, Norway and raised on the same diet. Fish were bath challenged with $L$. salmonis copepodids (30 copepodids/fish) at approximately 100 grams body weight. Standardised body weight at different water temperatures was achieved by adjusting the cumulative degree days (See supplementary Table 1). Fish were euthanised humanely with a lethal dose of anaesthesia and manually counted for lice by a team of trained staff. Mucosal samples were collected by manual scraping and stored at $-80^{\circ} \mathrm{C}$.

Chemical analysis of volatile collections:

Mucosal samples were thawed and $\sim 100 \mu \mathrm{L}$ of sample was transferred to a $20 \mathrm{~mL}$ headspace vial, flushed with nitrogen and capped with a teflon sealed screw cap. Volatile compounds were analysed using a Gerstel multipurpose sample automated dynamic head space system interfaced with an Agilent 7890B gas chromatograph (GC, Agilent, Palo Alto, CA, USA) and Agilent 5977B quadrupole mass selective detector. Incubation took place at $60^{\circ} \mathrm{C}$ for 5 min under agitation followed by purging $200 \mathrm{~mL}$ gas volume over Tenax GR activated coal for trapping volatile compounds. An additional step $\left(100 \mathrm{~mL}\right.$ nitrogen at $30^{\circ} \mathrm{C}$ for $16 \mathrm{~min}$.) was used to remove trapped moisture from the adsorbent before the adsorbent tube was transferred to the thermal desorption unit of the GC injector port, where volatiles were desorbed at $10^{\circ} \mathrm{C} / \mathrm{min}$ up to $300^{\circ} \mathrm{C}$ and transferred to the GC column kept at $30^{\circ} \mathrm{C}$. The compounds were separated on a DB-WAXetr column from Agilent $(0.25 \mathrm{~mm}$ i.d., $0.5 \mu \mathrm{m}$ film, $30 \mathrm{~m})$ using a Helium $(99.999 \%)$ carrier gas. The mass spectrometer was operated in electron impact (EI) mode at $70 \mathrm{eV}$ ionization energy and measuring positive ion fragments. The MS scan rate was from $\mathrm{m} / \mathrm{z}$ 33-500. Chemstation software (G1701CA version C.00.00, Agilent Technologies) was used to process the $\mathrm{GC} / \mathrm{MS}$ output data. Identification of the compounds was confirmed by comparing the measured mass spectra of the GC peaks with pure standards according to the NIST015 mass spectrum library. GC integrated peak area were used as raw data for the VOC expression. In addition, blank controls and a sample tube were analysed to check for possible background contamination.

Analysis of volatiles and lice infectivity:

Estimates of VOC expression levels were obtained using an ANOVA model accounting for effects of trial, water temperature and lice count group for the Temp population and genetic line for the Gen group. Phenotypic data for lice count and lice density were logarithmic base 10 transformed to ensure assumptions of normality and homoscedasticity were met. The lice counts were further analysed using linear mixed models with average 
information restricted maximum likelihood across all populations (Temp, Gen, Combined). The model accounted for trial, tank replicate nested in water temperature and random additive genetic effects of the pedigree. The broad sense heritability of VOCs was estimated using the same linear mixed effect models as lice count except the variance structure between families was tested in place of the additive genetic variance. Pearson's correlation was computed between the breeding value for lice count and VOC phenotypes. 
Table 1

Heritability estimates of Mucosal VOCs and their phenotypic correlation to salmon lice resistance

\begin{tabular}{|c|c|c|c|c|c|c|c|}
\hline Trial & Tank & $\begin{array}{l}\text { Water } \\
\text { temperature } \\
\left({ }^{\circ} \mathrm{C}\right)\end{array}$ & $\begin{array}{l}\text { Cumulative } \\
\text { degree } \\
\text { days at } \\
\text { Counting }\end{array}$ & Number of fish & $\begin{array}{l}\text { Average } \\
\text { weight } \\
\text { (grams) }\end{array}$ & $\begin{array}{l}\text { Average } \\
\log _{10} \\
\text { (lice } \\
\text { count) }\end{array}$ & $\begin{array}{l}\text { Sampled } \\
\text { for VOCs }\end{array}$ \\
\hline \multicolumn{8}{|l|}{ Temp 1} \\
\hline & 1 & 5 & 155 & 465 & 99.1 & 1.01 & 4 \\
\hline & 2 & 5 & 160 & 438 & 96.5 & 1.06 & 4 \\
\hline & 3 & 10 & 140 & 456 & 96.7 & 1.35 & 4 \\
\hline & 4 & 10 & 150 & 423 & 101.1 & 1.26 & 4 \\
\hline & 5 & 17 & 102 & 443 & 103.7 & 1.30 & 4 \\
\hline & 6 & 17 & 119 & 439 & 101.0 & 1.19 & 4 \\
\hline \multicolumn{8}{|l|}{ Temp 2} \\
\hline & 1 & 5 & 170 & 461 & 99.1 & 0.98 & 4 \\
\hline & 2 & 5 & 175 & 464 & 104.5 & 1.10 & 4 \\
\hline & 3 & 10 & 140 & 438 & 102.3 & 0.99 & 4 \\
\hline & 4 & 10 & 150 & 450 & 102.6 & 0.98 & 4 \\
\hline & 5 & 17 & 102 & 456 & 99.5 & 1.12 & 4 \\
\hline & 6 & 17 & 119 & 470 & 101.2 & 1.15 & 4 \\
\hline \multicolumn{8}{|l|}{ Gen } \\
\hline & 3 & 10 & 150 & 86 & 99.4 & 1.38 & 12 \\
\hline & 4 & 10 & 150 & 85 & 99.6 & 1.43 & 12 \\
\hline & $\begin{array}{l}\text { Lice } \\
\text { count }\end{array}$ & $\begin{array}{l}\text { 1-Penten-3- } \\
\text { ol }\end{array}$ & $\begin{array}{l}\text { 1-Octen-3- } \\
\text { ol }\end{array}$ & $\begin{array}{l}3,5,5- \\
\text { trimethylcyclohex- } \\
2 \text {-en-1-one }\end{array}$ & $\begin{array}{l}\text { 6- } \\
\text { Methyl- } \\
\text { 5- } \\
\text { hepten- } \\
\text { 2-one }\end{array}$ & Benzene & \\
\hline $\begin{array}{l}\text { Number of } \\
\text { Fish }\end{array}$ & 5749 & 48 & 72 & 24 & 72 & 24 & \\
\hline $\begin{array}{l}\text { Heritability } \\
\text { Broad } \\
\text { sense }\end{array}$ & $\begin{array}{l}0.23^{\star} \\
\pm \\
0.05\end{array}$ & N/A & $0.58 \pm 0.17$ & $0.47 \pm 0.23$ & $\begin{array}{l}0.37 \pm \\
0.20\end{array}$ & $\begin{array}{l}0.59 \pm \\
0.20\end{array}$ & \\
\hline
\end{tabular}

* Narrow sense heritability, \pm standard error 


\begin{tabular}{|c|c|c|c|c|c|c|c|}
\hline Trial & Tank & $\begin{array}{l}\text { Water } \\
\text { temperature } \\
\left({ }^{\circ} \mathrm{C}\right)\end{array}$ & $\begin{array}{l}\text { Cumulative } \\
\text { degree } \\
\text { days at } \\
\text { Counting }\end{array}$ & Number of fish & $\begin{array}{l}\text { Average } \\
\text { weight } \\
\text { (grams) }\end{array}$ & $\begin{array}{l}\text { Average } \\
\log _{10} \\
\text { (lice } \\
\text { count) }\end{array}$ & $\begin{array}{l}\text { Sampled } \\
\text { for VOCs }\end{array}$ \\
\hline
\end{tabular}

$\begin{array}{lllllll}\text { Correlation } & 1 & 0.65 \pm 0.11 & 0.59 \pm 0.11 & 0.74 \pm 0.14 & 0.50 \pm & 0.37 \pm \\ \text { to host } & & & & 0.10 & 0.20 \\ \text { genetic } & & & & \\ \text { potential } & & & & \\ \text { for } & & & & \\ \text { resistance } & & & & \end{array}$

* Narrow sense heritability, \pm standard error

\section{Declarations}

\section{Author Contributions}

CJ, GFD, LHJ, MWB, SB, BH designed the study

LHJ, MWB performed the lice challenge experiments

J-EH analysed the volatile compounds

GFD performed quantitative genetic analysis

MLA, CJ supervised the study.

$\mathrm{CJ}$ acquired funding

GFD, CJ wrote the manuscript.

All authors revised the manuscript.

Correspondence to Gareth Frank Difford

\section{Competing interests}

Baranski, M, S Boison are currently employed at MOWI and B Hillestad and H, Moghadam, are employed at Benchmark Genetics and all authors declare no competing interests.

\section{References}

1. Cressey, R. \& Patterson, C. Fossil Parasitic Copepods from a Lower Cretaceous Fish. Science (80-. ). 180, 1283-1285 (1973).

2. Yazawa, R. et al. EST and mitochondrial DNA sequences support a distinct Pacific form of salmon louse, Lepeophtheirus salmonis. Mar. Biotechnol. 10, 741-749 (2008). 
3. Lighten, J. et al. Evolutionary genetics of immunological supertypes reveals two faces of the Red Queen. Nat. Commun. 8, 1-10 (2017).

4. Marty, G. D., Saksida, S. M. \& Quinn, T. J. Relationship of farm salmon, sea lice, and wild salmon populations. Proc. Natl. Acad. Sci. 107, 22599-22604 (2010).

5. Ljungfeldt, L. E. R., Espedal, P. G., Nilsen, F., Skern-Mauritzen, M. \& Glover, K. A. A common-garden experiment to quantify evolutionary processes in copepods: The case of emamectin benzoate resistance in the parasitic sea louse Lepeophtheirus salmonis. BMC Evol. Biol. 14, (2014).

6. Barrett, L. T., Oppedal, F., Robinson, N. \& Dempster, T. Prevention not cure: a review of methods to avoid sea lice infestations in salmon aquaculture. Rev. Aquac. 1-17 (2020). doi:10.1111/raq.12456

7. Aaen, S. M., Helgesen, K. O., Bakke, M. J., Kaur, K. \& Horsberg, T. E. Drug resistance in sea lice: A threat to salmonid aquaculture. Trends Parasitol. 31, 72-81 (2015).

8. Houston, R. D. et al. Harnessing genomics to fast-track genetic improvement in aquaculture. Nat. Rev. Genet. (2020). doi:10.1038/s41576-020-0227-y

9. McBride, C. S. et al. Evolution of mosquito preference for humans linked to an odorant receptor. Nature 515, 222-227 (2014).

10. Weiss, L. C. et al. Identification of Chaoborus kairomone chemicals that induce defences in Daphnia. Nat. Chem. Biol. 14, 1133-1139 (2018).

11. Fields, D. M., Weissburg, M. J. \& Browman, H. I. Chemoreception in the salmon louse Lepeophtheirus salmonis: An electrophysiology approach. Dis. Aquat. Organ. 78, 161-168 (2007).

12. Devine, G. J. et al. Salmon lice, Lepeophtheirus salmonis, exhibit specific chemotactic responses to semiochemicals originating from the salmonid, Salmo salar. J. Chem. Ecol. 26, 1833-1847 (2000).

13. Ingvarsdóttir, A. et al. Semiochemical strategies for sea louse control: Host location cues. Pest Manag. Sci. 58, 537-545 (2002).

14. Ditzen, M., Pellegrino, M. \& Vosshall, L. B. Insect odorant receptors are molecular targets of the insect repellent DEET. Science (80- ). 319, 1838-1841 (2008).

15. Bailey, R. J. E. et al. The role of semiochemicals in host location and non-host avoidance by salmon louse (Lepeophtheirus salmonis) copepodids. Can. J. Fish. Aquat. Sci. 63, 448-456 (2006).

\section{Figures}




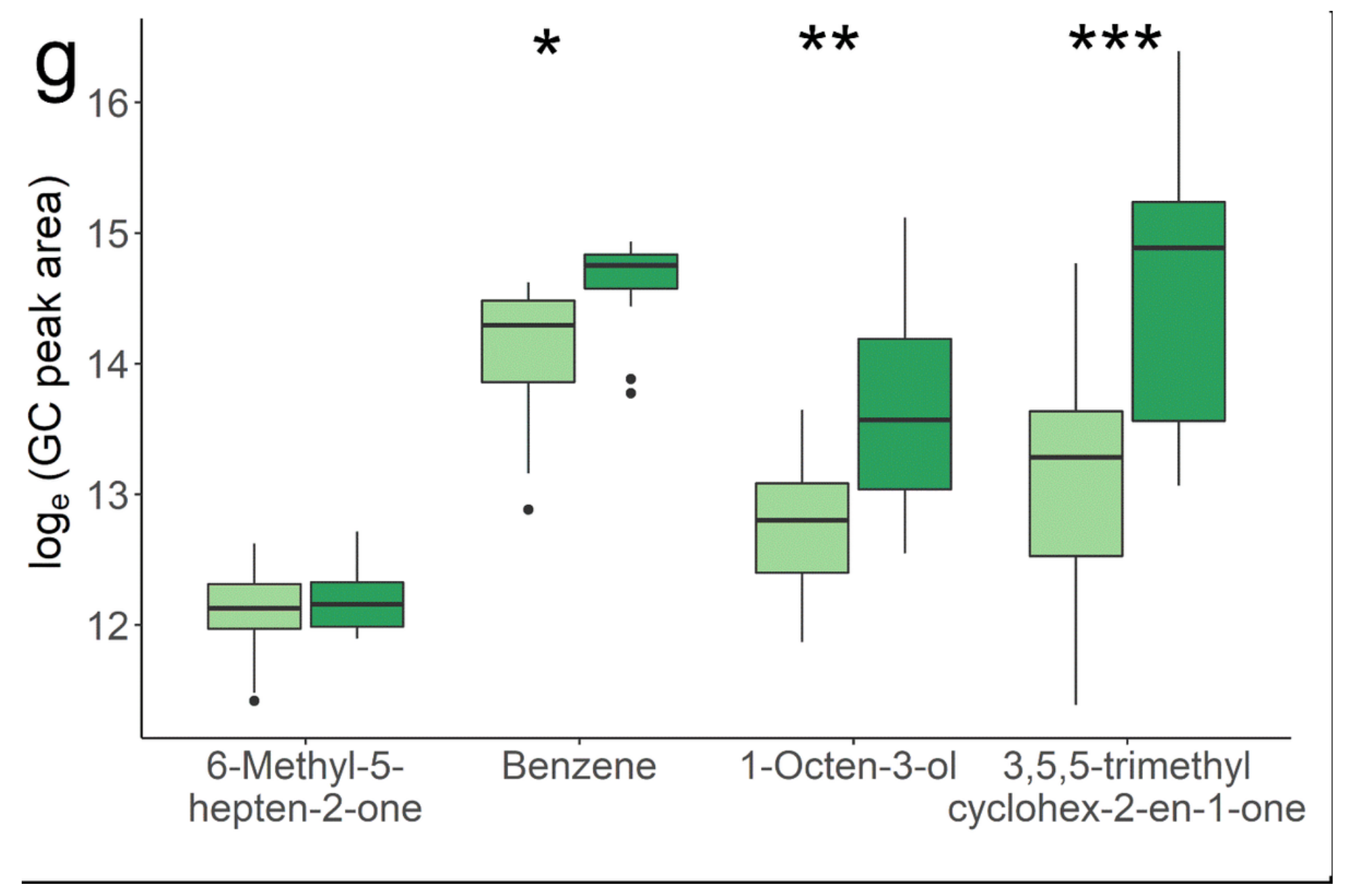

\section{Figure 1}

Skin mucosal VOC expression (as log10 GC peak area) is associated with differential copepodite infection across temperatures (Temp) and genetic resistance lines (Gen) to copepodite infection. a, relationship between lice count per host and lice density (count per unit surface area) across TEMP and GEN trials. b, Schematic of dynamic head space (DHS) gas chromatography (GC) mass spectrometry (MS). c, Venn diagram of VOC collection across TEMP and GEN. d, e, f, Differential expression of 1-penten-3-ol (d), 1-octen-3-ol (e), 6-Methyl-5hepten-2-one (f) across salmon with high and low lice count (High, Low) across culture temperatures $(5,10$ and $\left.17^{\circ} \mathrm{C}\right)$, significance level of Tukeys HSD $\left({ }^{*} p<0.05, * \star, p<0.01\right.$, $\left.* \star * p<0.001\right)$. (g) expression of VOC collections across genetically resistant (light green) and susceptible lines (dark green).

\section{Supplementary Files}

This is a list of supplementary files associated with this preprint. Click to download.

- si.docx 